\title{
The Status of Physical Education in Muslim Countries Compared to Saudi Women's Physical Education
}

\author{
Badr A. Fallatah \\ Division of Sport Science, Kangwon National University, Chuncheon, South Korea \\ badrfallatah@gmail.com \\ Seham M. Khan \\ Department of Physical Education, Sookmyung Women's University, Seoul, South Korea \\ Hong. Seok-Pyo \\ Division of Sport Science, Kangwon National University, Chuncheon, South Korea \\ Yousun Ko \\ Department of Physical Education, Sookmyung Women's University, Seoul, South Korea
}

\begin{abstract}
:
Recently in the Kingdom of Saudi Arabia very specific changes have been made to enable female population of the country to take part in physical activities. Saudi Arabia needs to follow the women's physical education curriculum in Bahrain and Qatar, which has been systematized ahead of Saudi Arabia in the main development for the development and modernization of women's education. This will bring remarkable growth to the Saudi Arabian women's future. But this new resolution faces criticism and resistance by a certain category of the population, fearing that it will impact in the religious side, whereas Saudi society is an Islamic society. Therefore, this study will investigate how education system can be effect on physical activity of women's school in Saudi Arabia as well as how to develop female education
\end{abstract}

Keywords: Saudi Arabia female students, Saudi women's Physical activity Education, physical education (PE), Bahrain, Qatar

\section{Introduction}

A global outlook on the equality of opportunities for boys and girls in PE programs in schools around the world, 91\% of countries provide equal PE participation opportunities for both gender groups. Nevertheless, there is still a fraction of the countries that either provides fewer opportunities or not at all. Until recently Kingdom of Saudi Arabia was not providing any physical education classes for girls in schools (14).

According to some critics or resistance to providing physical education classes for females, fearing that Saudi females will lose their modesty and respect due to the usual sportswear, the fear that women getting used to wearing it, which from their point it is contrary to the Islamic religion (which is , from their viewpoints, contrary to the Islamic Religion) . In addition, there are those who believe that sports, in general, is contrary to the nature of female, leading to the loss of female to their femininity (females' losing of their femininity or loss of females' femininity).

In the Saudi Vision to 2030,the implementation of physical education classes in the schools is 
crucial because it will allow a large part of the female population to be able to build a healthy body image leading to self-esteem and health care. As of 2017, as part of the Vision (15), the physical education category becomes available to female school students. Although there is no available data on the impact of participation in physical education classes in Saudi Arabia due to its recent implementation, there is a hard striving to investigate the school environment and provide future expectations.

In this study, we will investigate the current situation of the gymnasiums in the public female's schools, in addition to looking at previous studies of neighboring countries that are similar in the customs, traditions and general cultures such as Bahrain and Qatar. Although there are still gender differences in the requirements for physical education between girls and boys in these countries, the female physical education has been provided in schools early, in addition to the environment itself is in a much better position. Accordingly, the investigation of these two countries will allow us to present future expectations and to give a clearer understanding of potential perspectives.

No one can overlook that the implementation of physical education activities for girls in public schools is itself in itself is a huge achievement for the empowerment of Saudi women, but it is also important to consider the requirements of a physical education appropriate environment and attitudes needed by the general population in Saudi Arabia. This will allow us to develop assumptions and future proposals, in addition, to produce future research to assist in the development of physical education in Saudi Arabia in particular and in all countries in general.

\section{An Overview of Physical Education for Female in Bahrain, and Qatar:}

As implementation of the physical education classes is quite recent in most of the Gulf countries, there is an evident shortage of the related literature about sport in general, and specifically about women sports. Thus, we used all the limited sources available to provide an overview and make projections.

\section{Physical Education for Women in Bahrain}

In the case of Bahrain, since its very implementation in 1919 for boys and 1928 for girls government have been focusing on improving literacy rates and providing physical education for both genders. The government was providing funds to recruit education professionals from Arabic countries such as Palestine, Jordan, and Egypt. Since its very beginning, girls participated in PE classes wearing uniforms of shorts and shirts at all levels in gender-separated schools. This is a clear evidence of what government are doing regarding physical education implementation. There are also evidences that during 1940s female students were actively engaging in sports competitions that were occurring between schools [1].

One of the major developments in female physical education in Bahrain was that it was administered and taught by all female faculties. Although Bahrain represents a typical Islamic environment, where boys and girls had to attend gender-segregated schools, which is required by culture and traditions, schools and their facilities were and are still similar for both genders as well as curriculum is established at the similar level, even though male and female students learned slightly different set of skills and sports. For instance, for female students emphasis was put on table tennis, volleyball, and basketball.

With such developments, by 1970s there was a very well-established arena of female athletes in Bahrain, and some of the local sports federations started to accept women as prominent members, which provided support in practicing favorite sports. Moreover, female athletes were able to compete against each other in competitions held locally in Bahrain, as well as against other Arabian Gulf countries. Another important fact to be noted is that while holding those competitions, both female and male spectators could watch and support their teams at the same venues. Furthermore, nowadays 
government of Bahrain puts critical emphasis on further developing physical education for women not just as part of the primary education, but also providing degrees in higher institutions where women can receive bachelor and master degrees in PE and related majors [2].

\section{Physical Education and Sport Participation for Women in Qatar}

Qatar is considered a Muslim country but the female is not required to wear robes or cover their hair with a hijab unlike women in Saudi Arabia, in addition to being entitled to gained suffrage as in the males, they participate in sports in schools and elsewhere, this is different from what occurs in Saudi Arabia [3].

Among the Gulf countries, Qatar has made a remarkable investment in establishing an infrastructure for sports culture and educating its citizens about the benefits of an active lifestyle. The goals of promoting women's participation in sports and exercise have been officially incorporated into Qatar National Vision 2030 [4].

Qatar has a similar situation as in Bahrain, where physical education is implemented for both genders, and female students are taught by PE teachers specialized in female's education. Even more than Bahrain, Qatari government is heavily investing in establishing sports infrastructure and promoting women participation in sports.

\section{Physical Education in Saudi Arabia}

When it comes to female education in general and physical education in particular, there is an evident struggle in this regard in Saudi Arabia. Official education in Saudi Arabia dates back to the 1960s, when the first formal girls' school was opened in Riyadh [5]. This is extremely late comparing to other Arabic countries. Prior to this, informal schooling took place for both boys and girls, the aim was to teach religious principles only, such as learning the Qur'an, Hadith (the narrations of the Prophet), and Sunna (Prophet Mohammad's customary behavior and opinion on various issues drawn from the Hadith), to know how to pray and to follow the rules of behavior of the Muslim community. In the 1960s, schools were established to teach religious principles in addition to other sciences such as sciences, mathematics, social subjects and others.

Now, with the current government heavily investing into developing educational programs and infrastructures, under current government physical education classes were decided to be implemented as a part of the curriculum in primary schools for girls. Such decision has obviously a positive influence on the country, as it is critical for female empowerment in Saudi Arabia, on its own it promotes not only gender equality opportunities but also sports participation and healthy life style, it has been critically perceived by the conservative population.

Some aspects of the Islamic religion as wearing hijab, non-narrow dress, and non-attracting dress the recipient of a male gaze, in addition, all of which lead to the need to provide women's sports venues specialized for females separate from the males, to benefit women and enable them to carry out physical activities. There are groups of Muslims believe that the sports is dedicated to males only, that is contrary to the nature of female, leading to the loss of female femininity(6).

On the other hand, there is a strong agreement among Muslim that encourages women's sport, and there is an agreement that Islam encourages women to be physically active (7), (8), (9).

A relatively diverse sample of Egyptian women agreed that Islam promotes physical activity for women. The indication of that can be found in the prophet's running races with his wife Aishah "Mother of the Believers", both losing to her and beating her. Young Muslim Canadian women in Jiwani and Rail (7) indicated that in their view physical activity was a means to becoming a better Muslim. In the studies that we mentioned above, no Muslim women were reported to indicate that their religion restricted physical activity for women per se but rather believed that Islam requires Muslims to take care of themselves in a variety of ways, including keeping one's body healthy via 
physical activity.

Currently, the government strikes to implement physical education in schools, it needs to make a critical improvement in regard to the infrastructure. Especially in sports and fitness facilities that are a barely available for female and current venue where PE classes will be held are in poor conditions (10).

\section{Implications and Conclusion}

The fact that physical education for women is being implemented in Saudi Arabia is definitely a huge step forward and towards female empowerment. It is also a great promotion of physical activities and healthy lifestyle. Currently country struggles with attracting women to participate in physical activities. This can be explained by the fact that there are barely role models in that regard, as most of the Saudi female athletes are heavily criticized by the conservative population. In addition, there is a definite lack of fitness centers and gyms for women, and those that exist, are mostly located in the capital and are very few in numbers. Thus, physical education initiative can turn this situation around, and slowly attract women into sports.

In addition, there is a definite struggle when it comes to the overall health of Saudi people, and women in particular. According to the Gulf Cooperation Council (GCC) statement there are many chronic non-communicable diseases (NCDs) associated with obesity and diabetes [11]. In 2009, Kuwait, Oman, Saudi Arabia, and the UAE ranked globally in the top ten countries with a prevalence of obesity [12]. And in 2004, 56.4 percent of Bahraini men and 79 percent of Bahraini women were overweight or obese, while 64 percent of the men and 70 percent of the women were overweight or obese in Saudi Arabia [13].Thus it becomes crucial to start promoting physical activities early on.

When it comes to infrastructure and curriculum, believe that Saudi Arabia should follow a similar success example in customs, beliefs, and concepts based on what is stated in the Islamic religion such as Bahrain. Currently there is a lack of female trained professionals of Saudi origin that can train girl(s) during PE classes. Thus, by having its neighboring countries with much more developed sports environments, Saudi Arabia can employee female PE teachers from there, which will help to develop physical education on its early stages and grow future professionals. As for the establishment of gymnasiums, government of Saudi Arabia has to make its initiative and allocate funds for it.

In this study, we investigated the current state of the physical education initiative in Saudi Arabia, its sports environment, and infrastructure, as well as discussed current struggles and how they can be solved. In addition to studying the physical education cases in Bahrain and Qatar PE in female school population was offered much earlier and the environment itself is much better developed.

\section{References}

[1] T. Benn , G. Pfister \& H. Jawad, (Eds.).(2010). Muslim women and sport. Routledge. World Data on Education: Bahrain (2011)

[2] Saudi Women Push for Right to Play Sports.” 2012. Arabian Business

[3] ,March1.Accessed from http://www.arabianbusiness.com/saudiwomen-push-for-right-playsports-447831.html.

[4] Qatar National Vision 2030. General Secretariat for Development planning. 2008. Available at http://www.mdps.gov.qa. Retrieved 2016/04/12.

[5] M. AlMunajjed, (1997). Women in Saudi Arabia Today. United States: St. Martins Press.

[6] Abdul Razak, Maesam, S. Mohd Omar-Fauzee and Rozita. Abd-latif. 2010. "The Perspective of Arabic Muslim Women toward Sport Participation.” Journal of Asian Pacific Studies 1(2): 364-377.

[7] Jiwani, Nisara, Genevieve Rail. 2010. "Islam, Hijab and Young Shia Muslim Canadian 
Women's Discursive Constructions of Physical Activity." Sociology of Sport Journal 27: 251267.

[8] Walseth, Kristen. 2006. "Young Muslim Women and Sport: The Impact of Identity Work." Leisure Studies 25(1): 75-94 .

[9] Walseth, Kristen, and Kari Fasting. 2003. "Islam's View on Physical Activity and Sport: Egyptian Women Interpreting Islam.” International Review for the Sociology of Sport 38(1): 45-60.

[10]A. Hamdan, (2005). Women and Education in Saudi Arabia: Challenges and Achievements. International Education Journal, 6(1), 42-64.

[11]Bener, Abdulbari. 2006. "Prevalence of Obesity, Overweight, and Underweight in Qatari Adolescents." Food and Nutrition Bulletin 27(1): 39-45.

[12] O. Khatib, "Non communicable Diseases: Risk Factors and Regional Strategies for Prevention and Care." Eastern Mediterranean Health Journal 10(6) (2004): 778-88.

[13] Mabry, Ruth, Marina M. Reeves, Elizabeth G. Eakin, and Neville Owen. 2010. "Evidence of Physical Activity Participation among Men and Women in the Countries of the Gulf Cooperation Council: A Review." Obesity Reviews 11(6): 457-64.

[14]K. Hardman, C. Murphy, A.C. Routen \& Tones, S. (2014). World-wide survey of school physical education.

[15] Saudi Vision 2030. Available at http://vision2030.gov.sa/en 


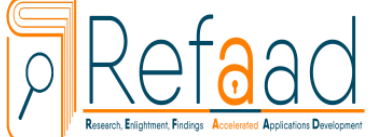

رفاد للدراسات والأبحاث

www.refaad.com

$$
\begin{aligned}
& \text { المجلة الدولية للدراسـات التربوية والنفسية }
\end{aligned}
$$

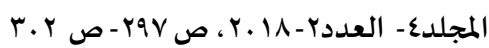

e-ISSN 2520-4149, p-ISSN 2520-4130
المجلة الدولية للدراسات التربوية والنفسية الثرات الثرات

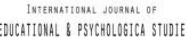

حالة التربية البدنية في الدول الإسلامية مقارنةً بالتربية البدنية للسعوديات

\author{
Badr A. Fallatah
}

Division of Sport Science, Kangwon National University, Chuncheon, South Korea badrfallatah@gmail.com

\title{
Seham M. Khan
}

Department of Physical Education, Sookmyung Women's University, Seoul, South Korea

\section{Hong. Seok-Pyo}

Division of Sport Science, Kangwon National University, Chuncheon, South Korea

\section{Yousun Ko}

Department of Physical Education, Sookmyung Women's University, Seoul, South Korea

\section{المللخص:}

في المملكة العبية السعودية في الآونة الأخيرة ، تم إجراء تغييرات محددة للغاية لتمكين الإناث من سكان البلاد من المشاركة في الأنشطة البدنية.

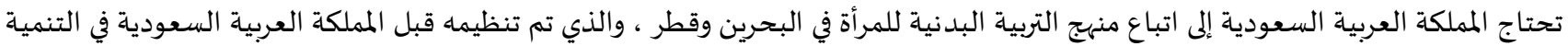

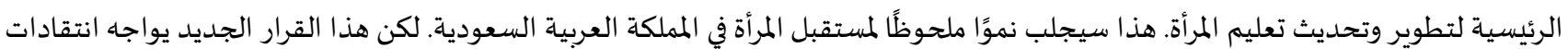
ومقاومة من قبل فئة معينة من السكان ، خوفا من أن يؤثر ذلك في الجانب الديني ، في حين أن المجتمع السعودي هو مجتمع إسلامي. لذلك ، ستقوم

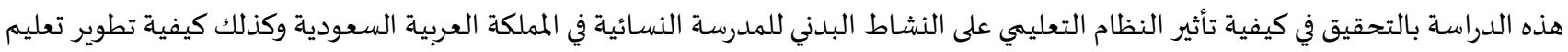

الكلمات المفتاحية: الطالبات السعوديات ، المرأة السعودية النشاط البدني التربية ، التربية البدنية (PE) ، البحرين ، قطر 